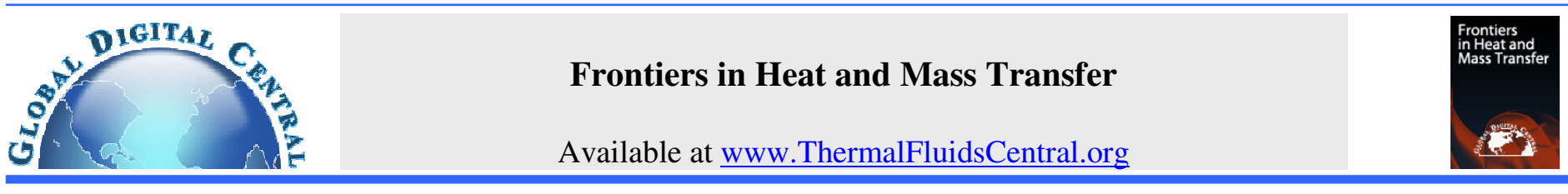

\title{
HEAT TRANSFER BASED NUMERICAL INVESTIGATION OF AIRCRAFT CABIN ENVIRONMENT FROM VARIOUS INLET CONDITIONS
}

\author{
Zhuohuan $\mathrm{Hu}^{\mathrm{a}, *}$ Lulu Wang ${ }^{\mathrm{a}}$, Hui Wang ${ }^{\mathrm{b}}$, Mo Yang ${ }^{\mathrm{a}}$ \\ ${ }^{a}$ School of Energy and Power Engineering, University of Shanghai for Science and Technology, Shanghai, 200093, China \\ ${ }^{b}$ National Computer Network and Information Safety Administration Center Shanghai Network Access Point, Shanghai, 201315, China
}

\begin{abstract}
A numerical investigation was conducted to study the heat transfer in an aircraft cabin and the effects of air distribution under different angle and inlet velocity conditions. The Reynolds-averaged Navier-Stokes equations and the low Reynolds number turbulence model were used to simulate the airflow in the cabin. Mathematical statistics was used to process the relevant data, and statistical results revealed that different inlet angles and velocities significantly affect air temperature and flow field. The study also determined a set of optimum matching inlet vane angles and inlet velocities that result in an environment which meets standard requirements and is energy saving. Additional studies were also conducted on the thermal comfort in cabin environments under optimal conditions. The conclusions of this thesis are scientific and feasible, and they can be used to improve the comfortableness of cabin environments.

Keywords: airliner cabin, numerical simulation, heat transfer, $P M V-P P D$.
\end{abstract}

\section{INTRODUCTION}

Ensuring flight security, increasing energy conservation, and improving the thermal comfort of passengers and pilots during flight are vital considerations in aircraft design (Shou et al., 2004; Zhang et al., 2007; Zhang et al., 2009). Pressure, temperature, velocity, and humidity are the main factors that influence comfortableness in aircraft cabins. Flow field, temperature field, and air quality in the cabin are related to relevant boundary conditions, such as inlet temperature, inlet velocity, inlet angle and position, and air humidity. As such, a comfortable cabin environment is realized under reasonable boundary conditions.

Previous studies have conducted numerical analyses on the heat and mass transfer involved in the internal fluid flow in aircraft cabins. J Günther et al. (2006) studied the airflow in an aircraft cabin using a combination of numerical simulation and experimentation by particle image velocimetry (PIV). Previous studies (Bosbach et al., 2006) have proven that the higher-order low Reynolds number turbulence model precisely fits the actual situation in simulating the flow in an aircraft cabin. Literature (Günther et al., 2006) also studied the flow of fresh air in the vicinity of a luggage compartment by building a cabin mock-up. Wang et al. (2008) and Yan et al. (2009) studied the unsteady airborne pollutant transport mechanism in an aircraft cabin mock-up without considering the heat source. Nevertheless, the results of their numerical simulation were in good agreement with those of the experiment. Bianco et al. (2009) established two- and three-dimensional simulation models of an executive aircraft cabin and investigated the thermal and velocity fields from the perspective of the external environment and fuselage material. The two-dimensional results were in agreement with the three-dimensional results. Kühn et al. (2009) studied the forced and mixed convection and received temperature field in the cabin mock-up of a passenger aircraft using PIV. Proper parameters are crucial in designing the air-conditioning of a passenger aircraft to ensure the thermal comfort of cabin passengers.

At the other end of the research spectrum, literatures (Poussou et al., 2010; Mazumdar et al., 2011; Mazumdar and Chen, 2007) investigated the influences of a moving human body on the airflow and contaminant transport in an aircraft cabin and measured the flow field and contaminant transport using planar laser-induced fluorescence and the techniques of particle image velocimetry. These experimental data were used to validate a Computational Fluid Dynamic (CFD) model. The results demonstrated that the CFD model effectively captures the characteristic flow features and contaminant transport observed in a small-scale model. Aakash and Chen (2012) developed a CFD model to predict the ozone distribution in an aircraft cabin. The agreement between the CFD results and available experimental data was generally good. The ozone concentration at the breathing zone in the cabin environment can effectively be used to assess the health risk to passengers and develop strategies that ensure a healthy cabin environment. Liu et al. (2012) studied pesticide concentrations and depositions after spraying part of an aircraft cabin. Furthermore, literatures (Isukapalli et al., 2013; You and Zhao, 2013) proposed a simplified method of quickly assessing the particle deposition rate in aircraft cabins and found that the influence of occupancy on the particle deposition rate of the cabin may be negligible.

The thermal comfort of the environment for passenger movement has also been increasingly investigated (Zhang, 2003; Maidment et al., 2004; Wang, 2009). Thermal comfort is a neither hot nor cold state to the environment, which is used to describe the degree of satisfaction on thermal environment. The referred research in the field of thermal comfort was carried out by Fanger in the 1970s, in which he developed an empirical model named predicted mean vote - predicted percentage dissatisfied (PMV-PPD) and the equations. He also pointed out that six

Corresponding author. Email: huzhuohuan@hotmail.com 
factors affected thermal sensation: four physical variables (air temperature, air velocity, relative humidity, mean radiant temperature), and two personal variables (clothing insulation and activity level) (Fanger, 1967). The PMV index represents the overwhelming number of people who feel hot or cold in the same environment. As such, the PMV index can be used to predict the thermal response of the human body to a thermal environment. And then, the results of the PMV equation are divided into seven levels to obtain PMV thermal sensation scale, from cold (-3) to hot (+3) in Table 1 (Charles, 2003). Although most people are satisfied with the thermal environment, some remain dissatisfied because of physiological differences. The PPD index represents the percentage of people who are dissatisfied with the thermal environment. The PMV-PPD standards were prescribed by the International Standardization Organization (ISO 7730) in1984 (Fanger, 1984).

Table 1 PMV thermal sensation scale.

\begin{tabular}{|c|c|c|c|c|c|c|c|}
\hline PMV value & -3 & -2 & -1 & 0 & 1 & 2 & 3 \\
\hline $\begin{array}{c}\text { Thermal } \\
\text { sensation }\end{array}$ & Cold & Cool & $\begin{array}{c}\text { Slightly } \\
\text { cool }\end{array}$ & Neutral & $\begin{array}{c}\text { Slightly } \\
\text { warm }\end{array}$ & Warm & Hot \\
\hline
\end{tabular}

Several studies have also been conducted on the thermal comfort of indoor environments. Yao and Chen (1997) simulated and analyzed indoor climates and the thermal comfort in rooms with natural ventilation and buried pipe ventilation systems using thermal dynamic simulation and CFD techniques in conjunction with the thermal comfort PMV/PPD model. The buried pipe ventilation system can improve indoor thermal comfort in hot climates. Yu and Zhang (2008) simulated flow and humidity fields at the peak of the indoor cooling load in isothermal and nonisothermal air supply with different floor temperatures. The parametric change in the air-conditioning system that satisfies the thermal comfort of the human body can be achieved using the PMV-PPD thermal comfort index. Schellen et al. (2013) proposed a new indoor thermophysiological model and simulation of the indoor environment around the human body's thermal sensation. The results show that the thermophysiological model combined with the thermal comfort model serves an important role in the effective evaluation of complex daily thermal environments. Buratti et al. (2013) studied the effect of glazing systems on the thermal comfort of a lecture room and determined the optimum glazing system that results in a comfortable environment.

The engineering context of the present study is composed of the thermal environment of a double-service aircraft that carries passengers and goods. This study focuses on the interior heat source and mixture of airflow; it considers the thermal radiation along the solid walls in the cabin as negligible. The landing stage is the most difficult task because it is not an independent stage in the actual processes of a flight. This study employs FLUENT to analyze the temperature and flow fields in an airliner cabin during the landing process. A set of optimum matching inlet vane angles and velocities that generate a comfortable environment are determined. Additional studies on thermal comfort using the PMV-PPD index verify that the conclusions of the present study are scientific and feasible, two qualities that have been typically disregarded in previous studies. In conclusion, the study of heat and mass transfer in aircraft cabins improves not only flight safety but also the energy-saving equipment and the comfort of passengers.

\section{MATHEMATICAL MODELS}

\subsection{Turbulence Models}

The actual situation of the heat and mass transfer in the workplace in an aircraft is quite complex. Thus, heat and mass transfer models should be simplified to obtain the gas state-space mathematical models in the cabin. This study is premised on the following assumptions:
- Air is an incompressible fluid that conforms to the Boussinesq hypothesis.

- The turbulent flow of the working medium in the cabin is steady.

- The thermal radiation around the solid walls and human body in the cabin can be neglected.

- The heat dissipation caused by the viscous force can be neglected because of the incompressible airflow at low speed.

The speed of airflow in the aircraft cabin is quite low, and the viscosity of the turbulence near the wall is slight. This study adopts the $\mathrm{k}-\varepsilon$ turbulence model that belongs to the Launder-Sharma low Reynolds number flow in the aircraft cabin (Zhai et al., 2007; Zhang et al., 2007).

\subsection{Governing Equations}

The continuity, Navier-Stokes, energy, and $\mathrm{k}-\varepsilon$ turbulence model equations were used to calculate the airflow. In the Cartesian coordinate space, three-dimensional governing equations (Shen and Yuan, 2009; Fan, 2008) in tensor forms were used to solve the problems of steadystate and incompressible turbulent flow. These equations are as follows:

$$
\begin{aligned}
& \frac{\partial}{\partial x_{j}}\left(\rho u_{i}\right)=0 \\
& \frac{\partial\left(\rho u_{i} u_{j}\right)}{\partial x_{j}}=-\frac{\partial p}{\partial x_{i}}+\frac{\partial}{\partial x_{j}}\left[\mu\left(\frac{\partial u_{i}}{\partial x_{j}}+\frac{\partial u_{j}}{\partial x_{i}}-\frac{2}{3} \delta_{i j} \frac{\partial u_{k}}{\partial x_{k}}\right)-\rho \overline{u_{i}^{\prime} u_{j}^{\prime}}\right] \\
& \frac{\partial\left(\rho u_{i} T\right)}{\partial x_{i}}=\frac{\partial}{\partial x_{i}}\left(\frac{\mu}{P_{r}} \frac{\partial T}{\partial x_{i}}-\rho \overline{u_{i}^{\prime} T^{\prime}}\right)+S_{T}
\end{aligned}
$$

The turbulent kinetic energy $\mathrm{k}$ equation and the dissipation rate $\varepsilon$ equation in the $\mathrm{k}-\varepsilon$ model are calculated as follows:

$$
\begin{aligned}
& \frac{\partial}{\partial x_{i}}\left(\rho u_{i} k\right)=\frac{\partial}{\partial x_{i}}\left[\left(\mu+\frac{\mu_{l}}{\sigma_{k}}\right) \frac{\partial k}{\partial x_{i}}\right]+G_{k}+G_{b}-\rho \varepsilon-Y_{M} \\
& \frac{\partial}{\partial x_{i}}\left(\rho u_{i} \varepsilon\right)=\frac{\partial}{\partial x_{i}}\left[\left(\mu+\frac{\mu_{l}}{\sigma_{\varepsilon}}\right) \frac{\partial \varepsilon}{\partial x_{i}}\right]+\frac{C_{1 \varepsilon} \varepsilon}{k}\left(G_{k}+C_{3 \varepsilon} G_{b}\right)-C_{2 \varepsilon} \rho \frac{\varepsilon^{2}}{k}
\end{aligned}
$$

where $\rho, p$ and $T$ are the air density $\left(\mathrm{kg} / \mathrm{m}^{3}\right)$, static pressure $\left(P_{a}\right)$, and air temperature $(K)$, respectively; $u_{i}$ is the velocity along the $x_{i}$ direction $(\mathrm{m} / \mathrm{s}) ; P_{r}$ is the Prandtl number; $\mu$ and $\mu_{l}$ are the laminar and turbulent dissipation rates, respectively; $S_{T}$ is the source term; $G_{k}$ is the turbulent kinetic energy caused by the average flow velocity gradient; $G_{b}$ is the turbulent kinetic energy caused by buoyancy; and $Y_{M}$ is the effect of the compressible turbulent flow pulsation expansion on the total dissipation rate. The viscosities of the turbulence coefficient are as follows: $\mu_{l}=\rho C_{\mu} k^{2} / \mathcal{E}, \quad C_{1 \varepsilon}=1.44, \quad C_{2 \varepsilon}=1.92$, and $C_{1 \varepsilon}=0.09$.

\subsection{Thermal Comfort Index}

The PMV-PPD method is based on the heat balance equation for human body and the PMV-PPD index (Yang and Chen, 2002; Liu, 2007; $\mathrm{Xu}, 2005)$, calculated as follows:

$$
\begin{aligned}
P M V= & {[0.303 \exp (-0.036 M)+0.028]\{M-W} \\
& -3.05\left[5.73-0.07(M-W)-P_{a}\right]-0.0173 M\left(5.87-P_{a}\right) \\
& -0.0014 M\left(34-t_{a}\right)-0.42(M-W-58) \\
& \left.-3.96 * 10^{-8} f_{d}\left[\left(t_{d}+273\right)^{4}-\left(t_{r}+273\right)^{4}\right]-f_{d} a_{c}\left(t_{d}-t_{a}\right)\right\} \\
P P D=100- & 95 \exp \left[-\left(0.03353 P M V^{4}+0.2179 P M V^{2}\right)\right]
\end{aligned}
$$


where $M$ is the body's metabolic heat production rate $\left(W / m^{2}\right), W$ is the body's external power $\left(W / m^{2}\right), \quad P_{a}$ is the partial pressure of the water vapor in the air $\left(k P_{a}\right), t_{a}$ is the air temperature of the surroundings $\left({ }^{\circ} \mathrm{C}\right)$, $t_{r}$ is the mean radiant temperature of the surroundings $\left({ }^{\circ} \mathrm{C}\right), t_{d}$ is the surface temperature of the clothes $\left({ }^{\circ} \mathrm{C}\right), f_{d}$ is the clothing area coefficient, and $a_{c}$ is the convective heat transfer coefficient.

The following assumptions are taken: $t_{a}=t_{\mathrm{r}}, \quad M=70 \mathrm{~W} / \mathrm{m}^{2}$, $W=0$, and $a_{c}=12 \cdot 1 \sqrt{v}$. Fanger pointed out that the climate formula should be multiplied by 0.5 to 1.0 in various countries and 0.7 in China as correction coefficients because the PMV test subjects are westerners (Ji et al., 2003).

\section{NUMERICAL ANALYSIS}

The velocity field, temperature field, and thermal comfort of the internal environment in the passenger and cargo aircraft cabins are analyzed below. Figure 1 shows the structure sketch of the aircraft cabin.

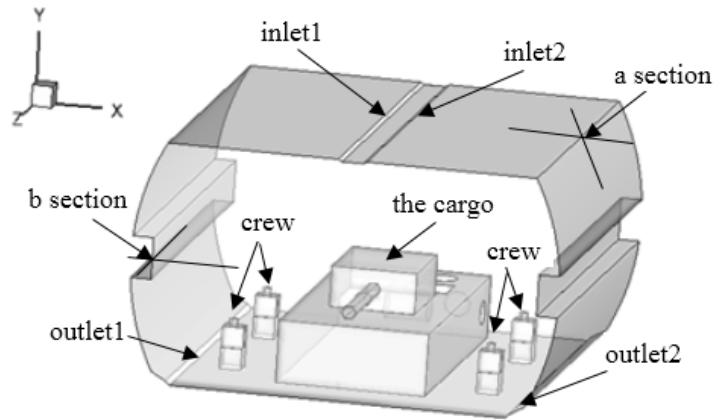

Fig. 1 The structure sketch of the aircraft cabin.

\subsection{Boundary Conditions}

The air inlet is based on boundary conditions, which assume an air inlet speed of $1 \mathrm{~m} / \mathrm{s}$ to $9 \mathrm{~m} / \mathrm{s}$ (Zhang and Ang, 2002). The magnitude of Reynolds numbers is between $10^{5}$ and $10^{6}$. And the inlet temperature is $20^{\circ} \mathrm{C}$; this model sets two symmetrical air inlets. The flow field in the cabin is examined under inlet angle conditions of $30^{\circ}, 45^{\circ}, 60^{\circ}, 75^{\circ}$, and $90^{\circ}$. Figure 2 shows various inlet angles of inlet 1 and inlet 2 .

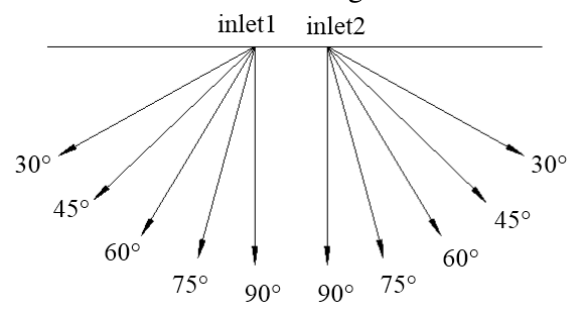

Fig. 2 Various inlet angles of inlet1 and inlet2.

The solid walls in the aircraft cabin are all set under non-slip conditions, and the speed is assumed as negligible. In this model, the internal walls of the cabin release heat outward. The human body is regarded as a source of heat, and the front and rear boundaries are set as planes of symmetry.

\subsection{Analysis of Flow and Temperature Fields}

The flow of air admission is controlled by changing the air inlet velocity. The final data are analyzed using the method of mathematical statistics. The influence of air distribution under different inlet air angles and velocities is also investigated. The inlet velocities of 3 and 6 $\mathrm{m} / \mathrm{s}$ are selected as the examples here because of the large number of images. For being convenient to study and analyze, cutting a center longitudinal section is a section, at the same time cutting a center horizontal section is b section, as shown in Figure 1. Figure 3 shows the velocity field of the vertical section under different inlet angles. Figure 4 shows the velocity field of the horizontal section under different inlet angles. Figure 5 shows the velocity variance of different inlet velocities under different inlet angles ( $\mathrm{z}$ section for the vertical section and $\mathrm{y}$ section for the horizontal section). Figures 3, 4, and 5 show the relatively obvious effects of the inlet angle and velocity on the flow field in the cabin.

Figure 6 shows the temperature field of the vertical section under different inlet angles. Figure 7 shows the temperature field of the horizontal section close to the walls under different inlet angles. Figure 8 shows the temperature variance of the different inlet velocities under different inlet angles. Figures 6,7 , and 8 show the relatively obvious effects of the inlet angle and velocity on the temperature field in the cabin.

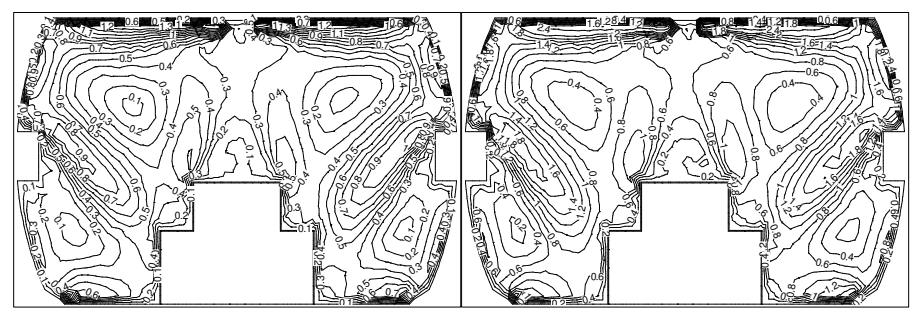

(a) $30^{\circ}: \mathrm{v}=3 \mathrm{~m} / \mathrm{s}$

(b) $30^{\circ}: \mathrm{v}=6 \mathrm{~m} / \mathrm{s}$

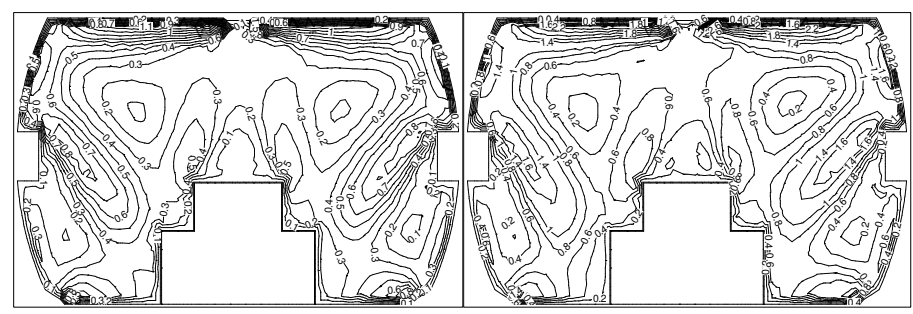

(c) $45^{\circ}: \mathrm{v}=3 \mathrm{~m} / \mathrm{s}$

(d) $45^{\circ}: \mathrm{v}=6 \mathrm{~m} / \mathrm{s}$

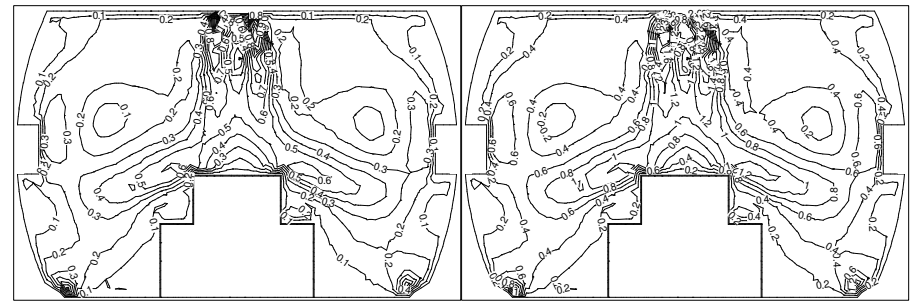

(e) $60^{\circ}: \mathrm{v}=3 \mathrm{~m} / \mathrm{s}$

(f) $60^{\circ}: v=6 \mathrm{~m} / \mathrm{s}$

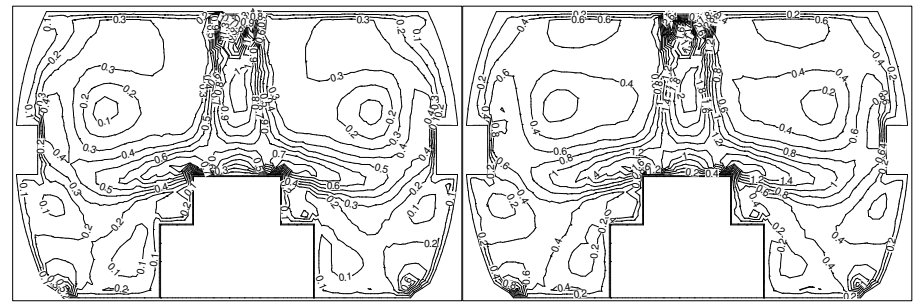

(g) $75^{\circ}: \mathrm{v}=3 \mathrm{~m} / \mathrm{s}$

(h) $75^{\circ}: \mathrm{v}=6 \mathrm{~m} / \mathrm{s}$

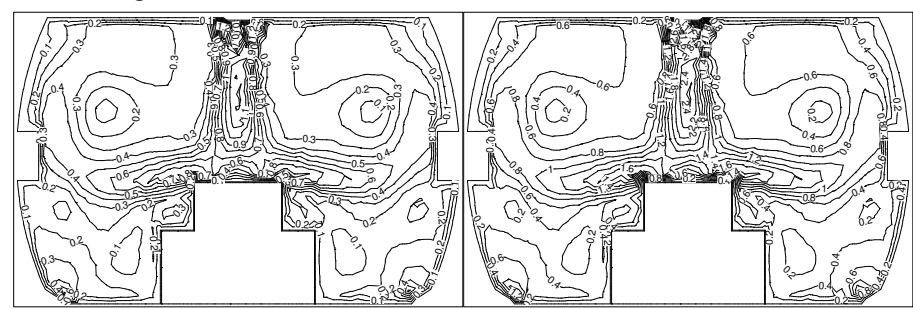

(i) $90^{\circ}: \mathrm{v}=3 \mathrm{~m} / \mathrm{s}$

(j) $90^{\circ}: \mathrm{v}=6 \mathrm{~m} / \mathrm{s}$

Fig. 3 Flow field of the center longitudinal section under different air inlet velocities. 


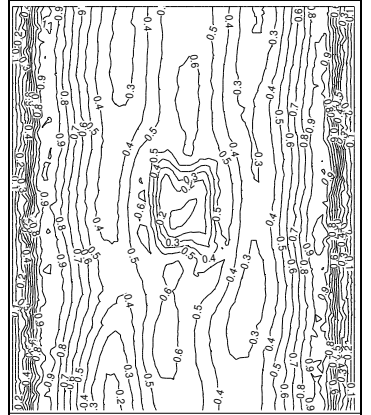

(a) $30^{\circ}: \mathrm{v}=3 \mathrm{~m} / \mathrm{s}$

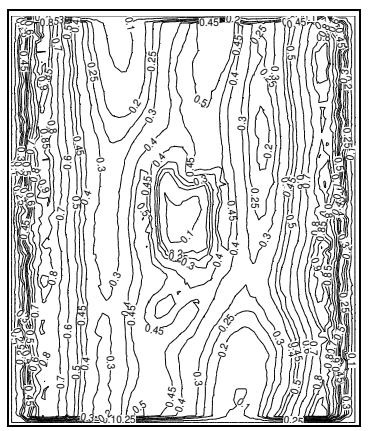

(c) $45^{\circ}: \mathrm{v}=3 \mathrm{~m} / \mathrm{s}$

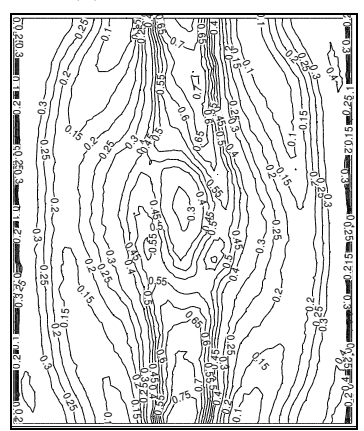

(e) $60^{\circ}: \mathrm{v}=3 \mathrm{~m} / \mathrm{s}$

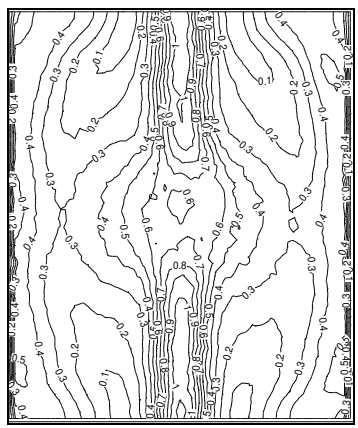

(g) $75^{\circ}: \mathrm{v}=3 \mathrm{~m} / \mathrm{s}$

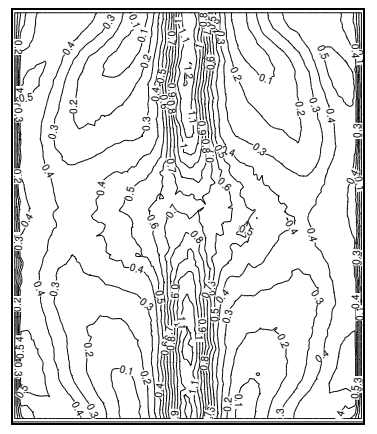

(i) $90^{\circ}: \mathrm{v}=3 \mathrm{~m} / \mathrm{s}$

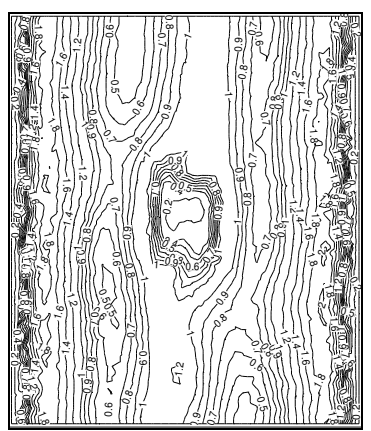

(b) $30^{\circ}: \mathrm{v}=6 \mathrm{~m} / \mathrm{s}$

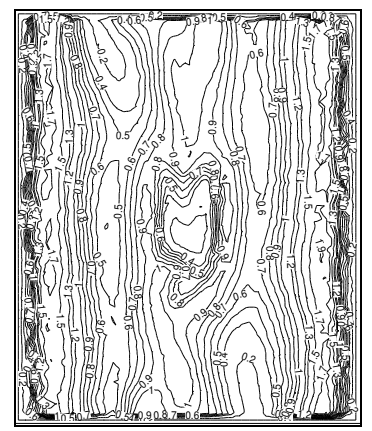

(d) $45^{\circ}: \mathrm{v}=6 \mathrm{~m} / \mathrm{s}$

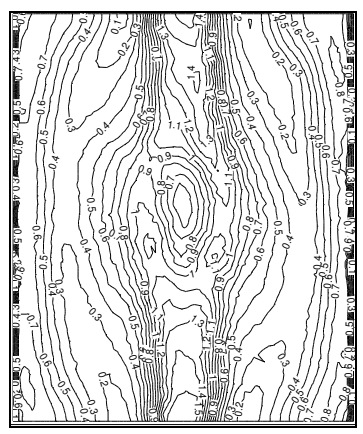

(f) $60^{\circ}: v=6 \mathrm{~m} / \mathrm{s}$

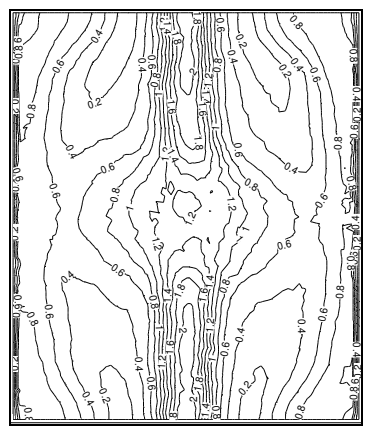

(h) $75^{\circ}: \mathrm{v}=6 \mathrm{~m} / \mathrm{s}$

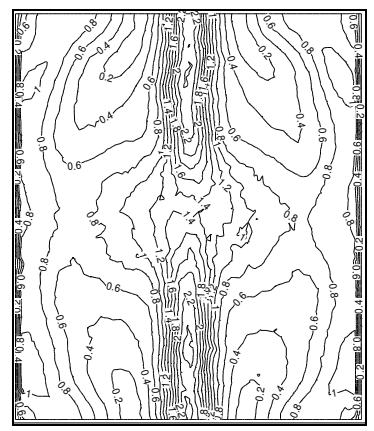

(j) $90^{\circ}: v=6 \mathrm{~m} / \mathrm{s}$
Fig. 4 Flow field of the center horizontal section under different air inlet velocities.
Several swirls occur in Figures 3 and 4 because of the blocking effect of the walls and objects in the cabin, which can lead to an increasingly balanced flow field. However, these swirls negatively influence the renewal of air from the perspective of mass transfer. In addition, the original inlet velocity at the inlet port rapidly decreases because of the effects of cabin air resistance and wall frictions. The velocity gradient of most parts of the cabin, excluding the inlet port, is lower than $2 \mathrm{~m} / \mathrm{s}$ when the inlet velocity increases from $1 \mathrm{~m} / \mathrm{s}$ to $9 \mathrm{~m} / \mathrm{s}$. Although the air velocity in the cabin increases along with the inlet velocity, the former increases only by approximately $0.2 \mathrm{~m} / \mathrm{s}$ to $0.4 \mathrm{~m} / \mathrm{s}$, whereas the latter increases by $3 \mathrm{~m} / \mathrm{s}$.

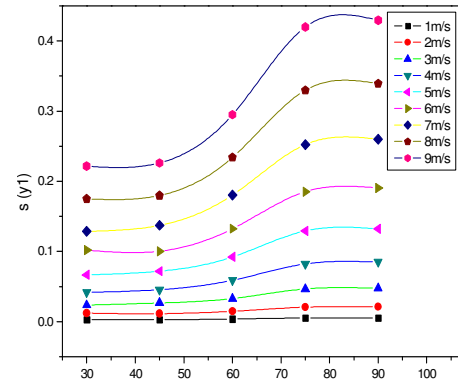

(a) y1 section

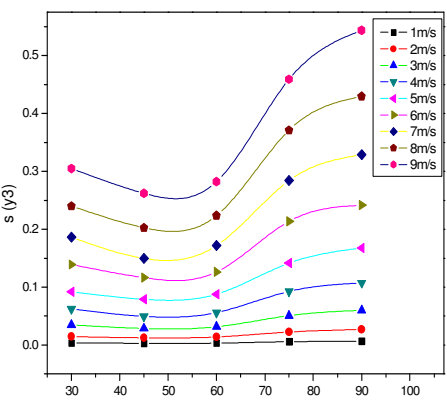

(c) y3 section

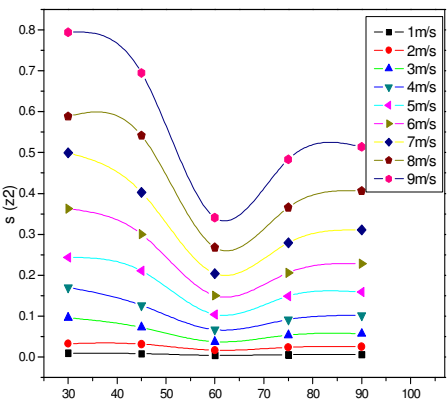

(e) z2 section

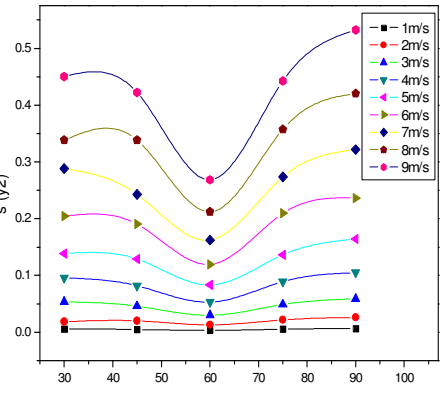

(b) y2 section

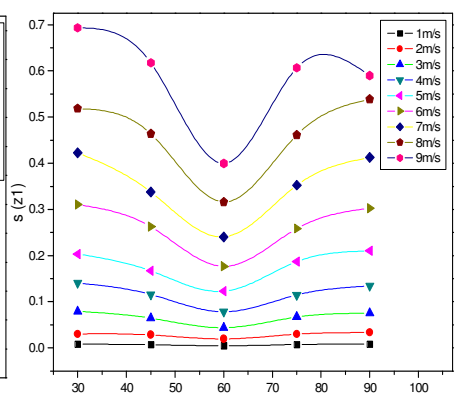

(d) z1 section

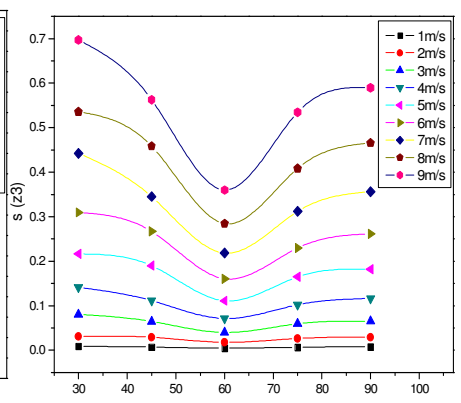

(f) z3 section

Fig. 5 Variance of velocity under different velocities according to the air inlet angles.

Figure 5 shows that noticeable changes occur in velocity variances under different velocities and similar variation rules in each section. In addition, the magnitude of the overall variance is small, and a relatively small variance around the $60^{\circ}$ inlet angle is detected. The velocity variance increases slightly as the inlet velocity increases. The slower the inlet velocity, the smaller the percentage of speed variation, and the more uniform the flow field, from the perspective of flow field uniformity. Based on mass transfer, an increase in inlet velocity improves the gas flow inside and outside, which in turn positively influences the renewal of the working medium. Hence, a smaller inlet velocity is not always better. 


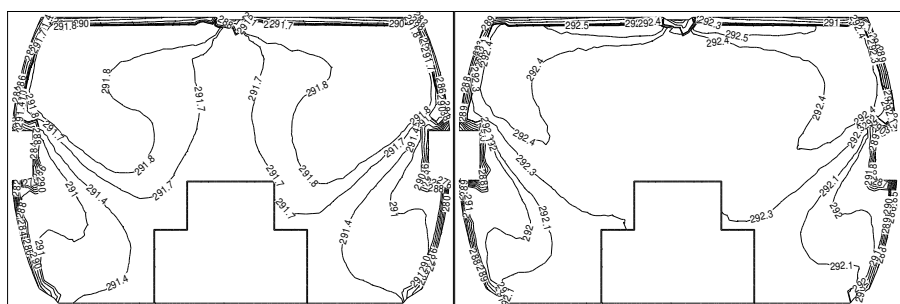

(a) $30^{\circ}: \mathrm{v}=3 \mathrm{~m} / \mathrm{s}$

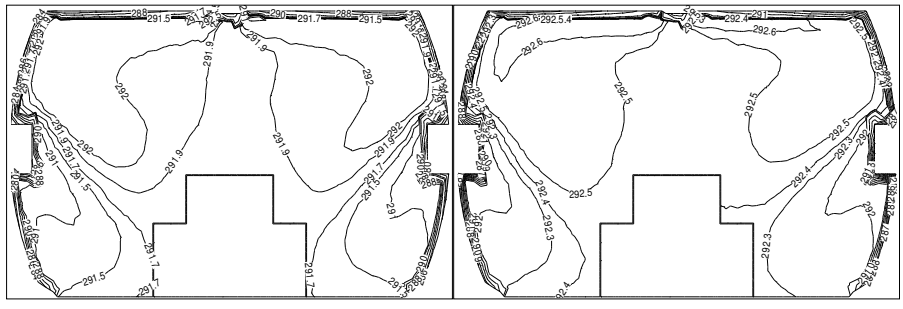

(c) $45^{\circ}: \mathrm{v}=3 \mathrm{~m} / \mathrm{s}$

(d) $45^{\circ}: \mathrm{v}=6 \mathrm{~m} / \mathrm{s}$

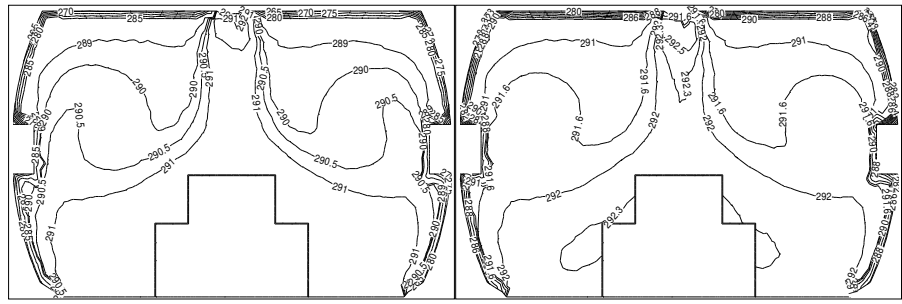

(e) $60^{\circ}: \mathrm{v}=3 \mathrm{~m} / \mathrm{s}$

(f) $60^{\circ}: \mathrm{v}=6 \mathrm{~m} / \mathrm{s}$

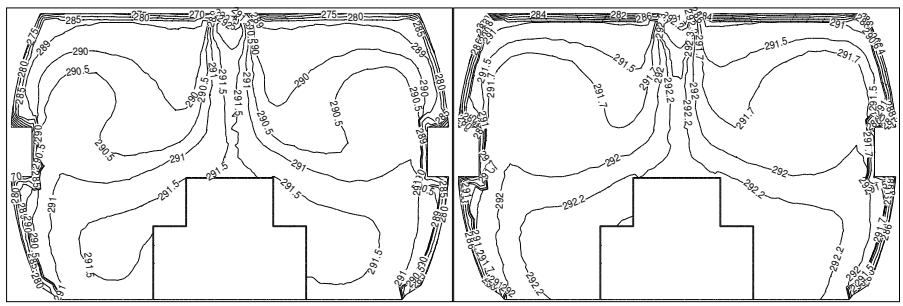

(g) $75^{\circ}: \mathrm{v}=3 \mathrm{~m} / \mathrm{s}$

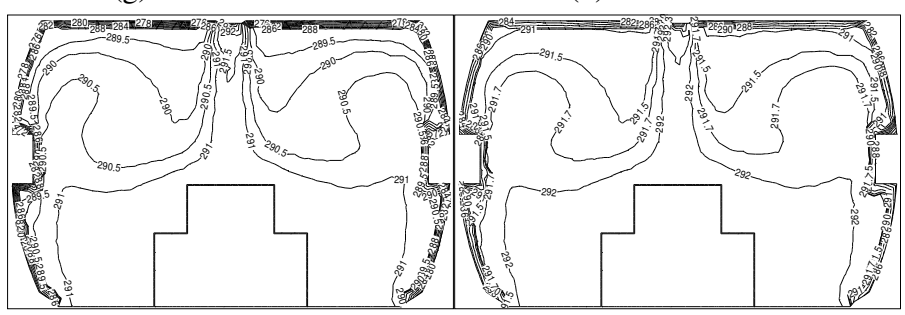

(j) $90^{\circ}: \mathrm{v}=3 \mathrm{~m} / \mathrm{s}$

(i) $90^{\circ}: \mathrm{v}=6 \mathrm{~m} / \mathrm{s}$

Fig. 6 Temperature field of the center longitudinal section under different air inlet velocities.

Figures 6 and 7 show that the temperature within a small distance from the wall changes dramatically because of heat dissipation, whereas the center temperature tends to be uniform. The temperature field in the entire cabin is inferior to the preceding temperature field with larger inlet flow rate. The effect of improving temperature comfort by increasing the inlet airflow is not significant when the temperature in the cabin is increased to a certain degree. In addition, the wall temperature improves and the temperature gradient slows down with the inlet velocity increasing.

Figure 8 shows that the temperature variance in the cabin becomes small because of the increase in the inlet velocity. The trend of the decrease in temperature variance is significant when the velocity increases from $1 \mathrm{~m} / \mathrm{s}$ to $3 \mathrm{~m} / \mathrm{s}$, but relatively insignificant when the velocity increases from $3 \mathrm{~m} / \mathrm{s}$ to $9 \mathrm{~m} / \mathrm{s}$. The order of magnitude of the temperature variance is relatively larger than that of the velocity variance. The previous analysis suggests that the temperature

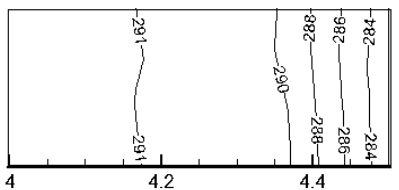

(a) $30^{\circ}: \mathrm{v}=3 \mathrm{~m} / \mathrm{s}$

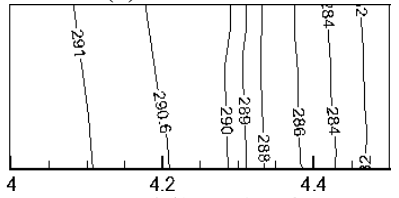

(c) $45^{\circ}: \mathrm{v}=3 \mathrm{~m} / \mathrm{s}$

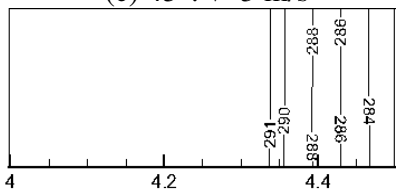

(e) $60^{\circ}: \mathrm{v}=3 \mathrm{~m} / \mathrm{s}$

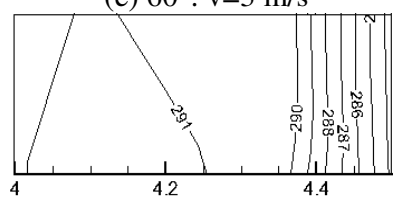

(g) $75^{\circ}: \mathrm{v}=3 \mathrm{~m} / \mathrm{s}$

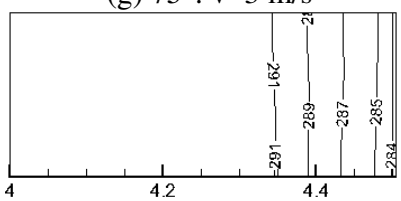

(i) $90^{\circ}: \mathrm{v}=3 \mathrm{~m} / \mathrm{s}$

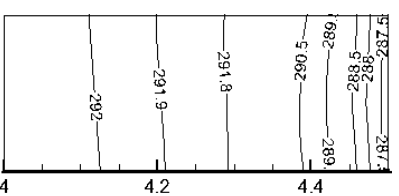

(b) $30^{\circ}: \mathrm{v}=6 \mathrm{~m} / \mathrm{s}$

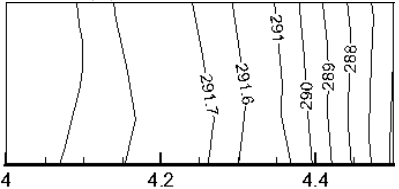

(d) $45^{\circ}: \mathrm{v}=6 \mathrm{~m} / \mathrm{s}$

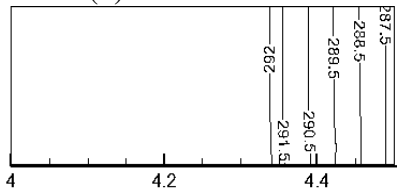

(f) $60^{\circ}: \mathrm{v}=6 \mathrm{~m} / \mathrm{s}$

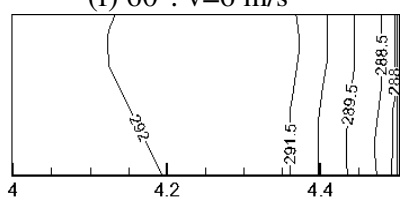

(h) $75^{\circ}: \mathrm{v}=6 \mathrm{~m} / \mathrm{s}$

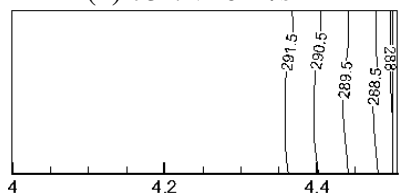

(j) $90^{\circ}: \mathrm{v}=6 \mathrm{~m} / \mathrm{s}$
Fig. 7 Isothermal diagram of the center cross section near the wall under different inlet velocities.

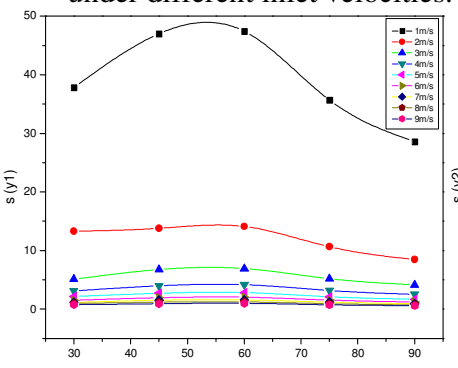

(a) y1 section

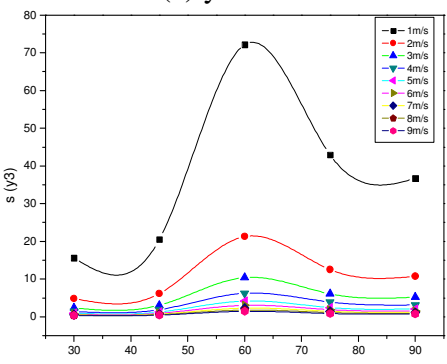

(c) y3 section

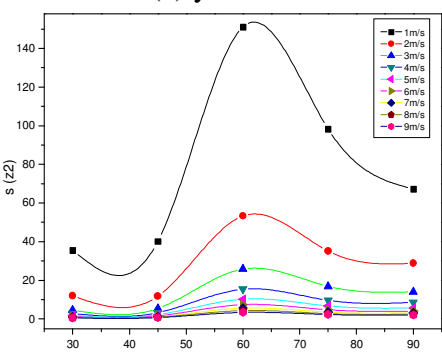

(e) z2 section

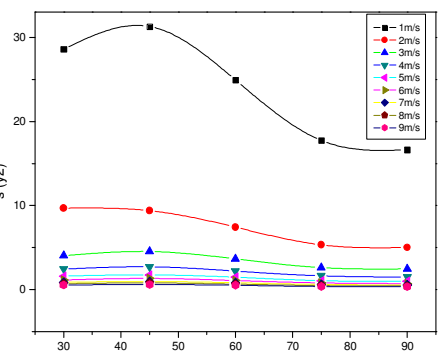

(b) y2 section

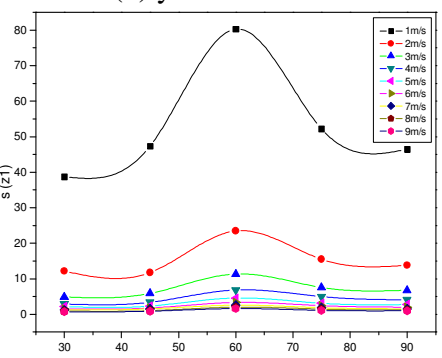

(d) z1 section

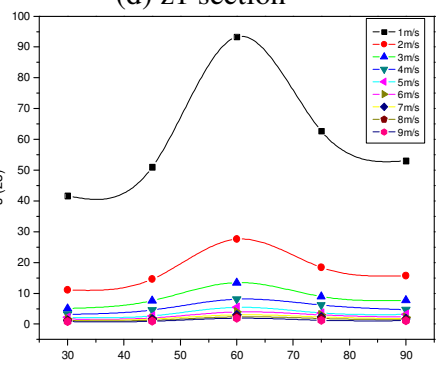

(f) $\mathrm{z} 3$ section
Fig. 8 Variance of temperature under different velocities according to the air inlet angles. 
fluctuation in the cabin does not conform to the principle of comfort when velocity is relatively small. Moreover, the effect of an improvement in temperature comfort caused by an increase in velocity is not obvious when the velocity of the cabin is relatively large. Figure 5 shows that the velocity fluctuation is fortified by an increase in the inlet velocity. Therefore, an inlet velocity with a mid-range value is the optimal velocity.

Table 2 Inlet mass flow corresponding to different inlet velocities.

\begin{tabular}{|c|c|c|c|c|c|c|c|c|c|}
\hline$v(m / s)$ & 1 & 2 & 3 & 4 & 5 & 6 & 7 & 8 & 9 \\
\hline $\mathrm{S}(\mathrm{kg} / \mathrm{s})$ & 2.3 & 4.7 & 7.1 & 9.4 & 11.8 & 14.2 & 16.6 & 18.9 & 21.3 \\
\hline
\end{tabular}

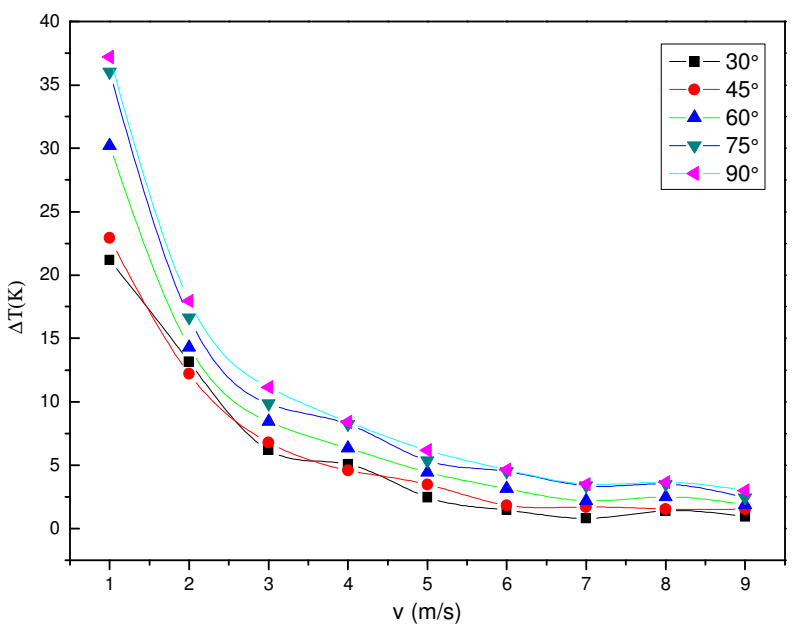

Fig. 9 The difference between maximum temperature and minimum temperature corresponding to different inlet velocities.

Table 2 shows inlet flow rate increase with the inlet velocity increasing and more energy will be consumed to produce the required flow rate. However, energy consumption increases and temperature difference decreases as the inlet flow increases, as shown in Figure 9. On the premise of satisfying occupant comfort, It is hope to save energy. According to aviation medicine, the normal comfort temperature region should be between 15 and $26^{\circ} \mathrm{C}$ and the temperature field should be uniform. Furthermore, The deviation of the cabin temperature along the vertical and horizontal directions from regulations should not be too large. The difference between maximum temperature and minimum temperature should be within the range of $6^{\circ} \mathrm{C}$. The temperature of the cabin wall, floor, and top wall should be consistent with the cabin temperature. Otherwise, the passengers will feel uncomfortable because of the influence of thermal radiation and convection. Consequently, the comfort demand can be satisfied basically, when the air inlet velocity is not less than $3 \mathrm{~m} / \mathrm{s}$; and the energy consumption can be reduced to the extent possible, when the air inlet velocity is between 3 and $6 \mathrm{~m} / \mathrm{s}$.

\subsection{Analysis of PMV-PPD}

The air thermal comfort in the cabin is discussed here based on the previous results. The PMV field of air comfort in the cabin and the PPD were obtained through a simulation under inlet angle conditions of $30^{\circ}$ and $45^{\circ}$ and inlet velocity of $1 \mathrm{~m} / \mathrm{s}$ to $9 \mathrm{~m} / \mathrm{s}$. The inlet velocities of 3 and $6 \mathrm{~m} / \mathrm{s}$ are selected as the examples here because of the large number of images. Figure 9 shows the PMV and PPD fields of a cross section.

The PMV in the cabin is a function of air temperature and air speed (other parameters have constant values), and PPD is a function of PMV. Figure 10 shows that the PMV field is similar to the velocity distribution law in the cabin, given that the temperature gradient in the cabin is small and the speed rate is large. Moreover, the PMV gradient is large near the cabin walls and the objects in the cabin because of the fast speed rate and the intense temperature changes. PPD field changes depending only on PMV.

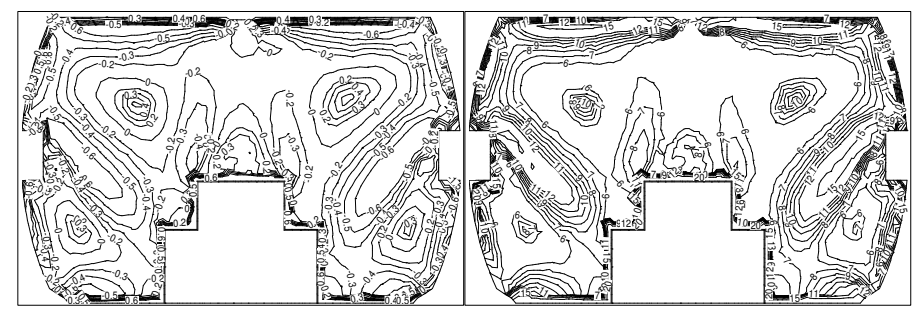

(a) $30^{\circ}: 3 \mathrm{~m} / \mathrm{s} \quad \mathrm{PMV}$

(b) $30^{\circ}: 3 \mathrm{~m} / \mathrm{s} \quad$ PPD

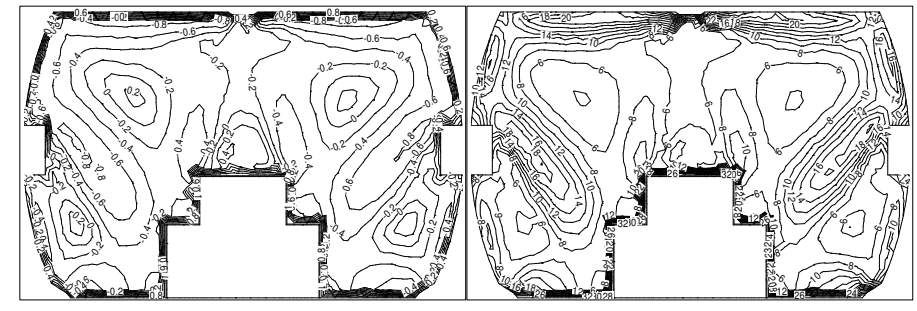

(c) $30^{\circ}: 6 \mathrm{~m} / \mathrm{s} \quad$ PMV

(d) $30^{\circ}: 6 \mathrm{~m} / \mathrm{s} \quad$ PPD

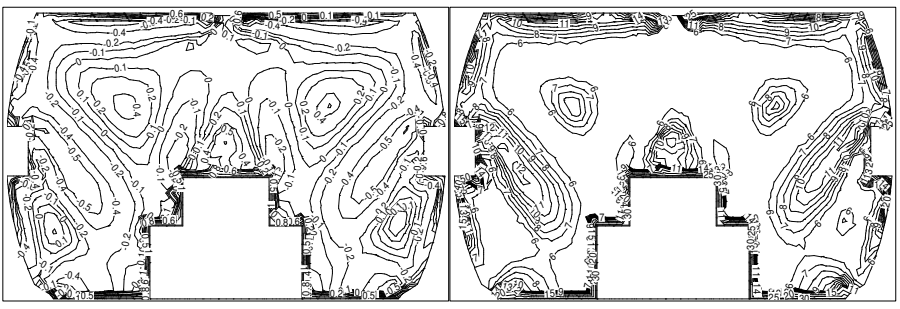

(e) $45^{\circ}: 3 \mathrm{~m} / \mathrm{s} \quad$ PMV

(f) $45^{\circ}: 3 \mathrm{~m} / \mathrm{s} \quad \mathrm{PPD}$

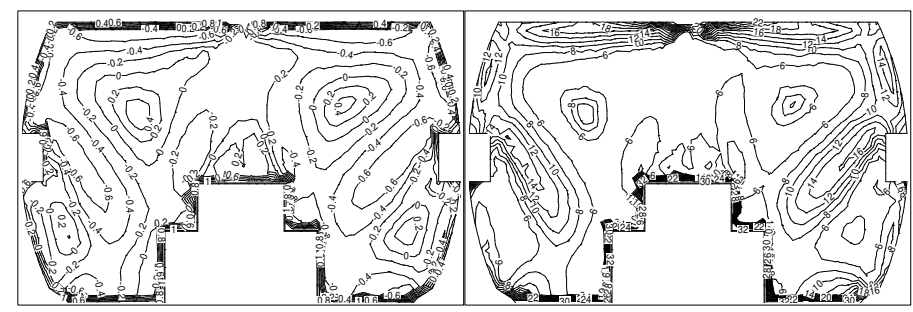

(g) $45^{\circ}: 6 \mathrm{~m} / \mathrm{s} \quad$ PMV

(h) $45^{\circ}: 6 \mathrm{~m} / \mathrm{s}$

PPD

Fig. 10 PMV and PPD fields of a cross section.

Table 3 PMV range under different inlet velocities in the cabin.

\begin{tabular}{|c|c|c|c|c|}
\hline$P M V$ & $30^{\circ}(\min )$ & $30^{\circ}(\max )$ & $45^{\circ}(\min )$ & $45^{\circ}(\max )$ \\
\hline $1 \mathrm{~m} / \mathrm{s}$ & -2.31 & 0.75 & -2.51 & 0.82 \\
\hline $2 \mathrm{~m} / \mathrm{s}$ & -1.63 & 1.03 & -1.76 & 1.07 \\
\hline $3 \mathrm{~m} / \mathrm{s}$ & -1.24 & 1.14 & -1.3 & 1.17 \\
\hline $4 \mathrm{~m} / \mathrm{s}$ & -1.14 & 1.2 & -1.17 & 1.22 \\
\hline $5 \mathrm{~m} / \mathrm{s}$ & -1.1 & 1.22 & -1.02 & 1.25 \\
\hline $6 \mathrm{~m} / \mathrm{s}$ & -0.94 & 1.23 & -0.99 & 1.27 \\
\hline $7 \mathrm{~m} / \mathrm{s}$ & -0.93 & 1.25 & -0.98 & 1.28 \\
\hline $8 \mathrm{~m} / \mathrm{s}$ & -0.92 & 1.27 & -0.96 & 1.29 \\
\hline $9 \mathrm{~m} / \mathrm{s}$ & -0.9 & 1.28 & -0.92 & 1.29 \\
\hline
\end{tabular}

According to the Code for Design of Heating Ventilation and Air Conditioning, the thermal comfort of heating and air-conditioning in a room should follow the PMV and PPD index determination of moderate thermal environment and the regulations of thermal comfort conditions (Hua et al., 2011). It must also have the average PMV and PPD. The ideal PMV and PPD index values are as follows: the PMV index is between -1 and +1 , and the PPD index is not greater than 27\%. Figure 10 and Table 3 show that the PMV index is between -1.3 and +1.3 with a velocity not lower than $3 \mathrm{~m} / \mathrm{s}$ and that the PMV in most cabin regions is not beyond the range of -1 to 1 . The PPD in most cabin regions is not greater than $20 \%$, and the PPD index near the wall surface exceeds $20 \%$. Hence, the conclusions meet the criteria of thermal comfort. 


\section{CONCLUSIONS}

Pressure, temperature, velocity, and humidity are the main factors that influence comfortableness in an aircraft cabin. Flow field, temperature field and air quality in the cabin are related to relevant boundary conditions, such as inlet temperature, inlet velocity, inlet angle and position, and air humidity. A comfortable cabin environment is realized under reasonable boundary conditions. The average Reynolds equation and the low Reynolds number turbulence model were used to simulate the cabin airflow. A numerical investigation was conducted on the heat transfer in a cabin to investigate the effects of air distribution under different angle and inlet velocity conditions. Additional studies were also conducted on the thermal comfort of the cabin environment under these inlet conditions.

The results of the analysis are as follows:

- The velocity variance is at the minimum level, and the temperature variance is at the maximum level, when the air inlet angle is $60^{\circ}$. The temperature difference between the wall and human body is too large and does not satisfy the comfort requirement. As such, the comfort demand of passengers is satisfied when the air inlet angle in the region is between $35^{\circ}$ and $45^{\circ}$.

- The velocity variance in the cabin increases (i.e., the increase in velocity fluctuation) as the inlet flow increases, and the order of magnitude for the variance is relatively small.

- The temperature variance in the cabin decreases (i.e., an increasingly uniform temperature field) as the inlet flow increases. The trend of the decrease in temperature variance is significant when the velocity increases from $1 \mathrm{~m} / \mathrm{s}$ to $3 \mathrm{~m} / \mathrm{s}$, but relatively insignificant when the velocity increases from 3 $\mathrm{m} / \mathrm{s}$ to $9 \mathrm{~m} / \mathrm{s}$.

- $\quad$ Both energy consumption and velocity fluctuation increase as the inlet flow increases and the temperature distribution becomes increasingly uniform. Consequently, the comfort demand can be satisfied, and the energy consumption can be reduced to the extent possible, when the air inlet velocity is between 3 and $6 \mathrm{~m} / \mathrm{s}$.

- These conclusions prove that the PMV-PPD index of the cabin environment of comfort can satisfy the human body's basic thermal comfort demand using small inlet angles and reasonable inlet velocities

This study provides a mathematical model that reflects the actual situation for future research and optimization design of control system for comfortable cabin environments.

\section{ACKNOWLEDGEMENTS}

This work is supported in part by National Science Foundation of China (51276118).

\section{REFERENCES}

Bosbach, J., Pennecot, J., Wagner, C., Raffel, M., Lerche, T., and Repp, S., 2006, "Experimental and Numerical Simulations of Turbulent Ventilation in Aircraft Cabins," Energy, 31(5), 694-705. http://dx.doi.org/10.1016/j.energy.2005.04.015

Bianco, V., Manca, O., Nardini, S., and Roma, M., 2009, "Numerical Investigation of Transient Thermal and Fluidynamic Fields in an Executive Aircraft Cabin," Applied Thermal Engineering, 29(16), 3418-3425.

http://dx.doi.org/10.1016/j.applthermaleng.2009.05.020

Buratti, C., Moretti, E., Belloni, E., and Cotana, F., 2013, "Unsteady Simulation of Energy Performance and Thermal Comfort in Nonresidential Buildings," Building \& Environment, 59(328), 482-491. http://dx.doi.org/10.1016/j.buildenv.2012.09.015
Charles, K. E., 2003, "Fanger's Thermal Comfort and Draught Models," Institute for Research in Construction National Research Council of Canada, Ottawa, K1A 0R6, Canada IRC Research Report RR-162 October, 10. http://dx.doi.org/10.4224/20378865

Fanger, P. O., 1967, "Calculation of Thermal Comfort, Introduction of a Basic Comfort Equation," ASHRAE transactions, 73(2), III-4.

Fanger, P. O., 1984, "Moderate Thermal Environments Determination of the PMV and PPD Indices and Specification of the Conditions for Thermal Comfort," ISO 7730.

Fan J., 2008, "FLUENT Advanced Application and Example Analysis," Tsinghua University Press.

Günther, G., Bosbach, J., Pennecot, J., Wagner, C., Lerche, T., and Gores, I., 2006, "Experimental and Numerical Simulations of Idealized Aircraft Cabin Flows," Aerospace Science \& Technology, 10(7), 563573.

\section{http://dx.doi.org/10.1016/j.ast.2006.02.003}

Hua, D., Li, T., Liu, W., Jin, S., and Q., 2011, "Moderate Thermal Environment-determination of the PMV and PPD Indices and Specification of the Conditions for Thermal Comfort," Beijing, National Standards Publishing House.

Isukapalli, S. S., Mazumdar, S., George, P., Wei, B., Jones, B., and Weisel, C. P., 2013, "Computational Fluid Dynamics Modeling of Transport and Deposition of Pesticides in an Aircraft Cabin," Atmospheric Environment, 68(1), 198-207.

http://dx.doi.org/10.1016/j.atmosenv.2012.11.019

Ji, X., Li, G., and Dai, Z., 2003, "Influencing Factors and the Research Progress on Forecasting and Evaluating Indoor Thermal Comfort," Journal of Hygiene Research, 32(3), 295-299.

Kühn, M., Bosbach, J., and Wagner, C., 2009, "Experimental Parametric Study of Forced and Mixed Convection in a Passenger Aircraft Cabin Mock-up," Building \& Environment, 44(5), 961-970. http://dx.doi.org/10.1016/j.buildenv.2008.06.020

Liu, W., Mazumdar, S., Zhang, Z., Poussou, S. B., Liu, J., and Lin, C. H., 2012, "State-of-the-art Methods for Studying Air Distributions in Commercial Airliner Cabins," Building \& Environment, 47: 5-12. http://dx.doi.org/10.1016/j.buildenv.2011.07.005

Liu, X., 2007, "The Study of Thermal Comfort and Energy Saving Schemes for Hospital," Refrigeration and Air Conditioning, 21(4): 8589.

Mazumdar, S., Poussou, S. B., Lin, C. H., Isukapalli, S. S., Plesniak, M. W., and Chen, Q., 2011, "Impact of Scaling and Body Movement on Contaminant Transport in Airliner Cabins," Atmospheric Environment, 45(33), 6019-6028.

http://dx.doi.org/10.1016/j.atmosenv.2011.07.049

Mazumdar, S., and Chen, Q., 2007, "Impact of Moving Bodies on Airflow and Contaminant Transport Inside Aircraft Cabins," Proceedings of Roomvent, $10^{\text {th }}$ International Conference on Air Distribution in Rooms, Helsinki, Finland.

Maidment, G., Missenden, J., and Ampofo, F., 2004, "Underground Railway Environment in the UK part 1: Review of Thermal Comfort," Applied Thermal Engineering, 24(5), 611-631. http://dx.doi.org/10.1016/j.applthermaleng.2003.10.017

Poussou, S. B., Mazumdar, S., Plesniak, M. W., Sojka, P. E., and Chen, Q., 2010, "Flow and Contaminant Transport in an Airliner Cabin Induced by a Moving Body: Model Experiments and CFD Predictions," Atmospheric Environment, 44(24), 2830-2839.

http://dx.doi.org/10.1016/j.atmosenv.2010.04.053 
Rai, A. C., and Chen, Q., 2012, "Simulations of Ozone Distributions in an Aircraft Cabin Using Computational Fluid Dynamics," Atmospheric Environment, 54(5), 348-357. http://dx.doi.org/10.1016/j.atmosenv.2012.02.010

Shou, R.Z., He, H.S., 2004, “Aircraft's Environment Control,” Beijing University of Aeronautics and Astronautics Press, Beijing.

Schellen, L., Loomans, M. G. L. C., Kingma, B. R. M., Wit, M. H. D., Frijns, A. J. H., and Lichtenbelt, W. D. V. M., 2013, "The Use of a Thermophysiological Model in the Built Environment to Predict Thermal Sensation: Coupling with the Indoor Environment and Thermal Sensation," Building \& Environment, 59, 10-22. http://dx.doi.org/10.1016/j.buildenv.2012.07.010

Shen, H., and Yuan, X., 2009, "Numerical Simulation and Experiment on Air Flow and Heat Transfer in Fighter Plane Cockpit," Acta Aeronautica Et Astronautica Sinica, 30(1), 30-39.

Wang, A., Zhang, Y., Sun, Y., and Wang, X., 2008, "Experimental Study of Ventilation Effectiveness and Air Velocity Distribution in an Aircraft Cabin Mockup," Building \& Environment, 43, 337-343. http://dx.doi.org/10.1016/j.buildenv.2006.02.024

Wang, Z., 2006, “A Field Study of the Thermal Comfort in Residential Buildings in Harbin," Building \& Environment, 41(8), 1034-1039. http://dx.doi.org/10.1016/j.buildenv.2005.04.020

Xu, J., 2005, "Discussion on the Application Range of the PMV Equation," Journal of Chongqing Architecture University, 27(3), 13-18.

Yan, W., Zhang, Y., Sun, Y., and Li, D., 2009, "Experimental and CFD Study of Unsteady Airborne Pollutant Transport within an Aircraft Cabin Mock-up," Building \& Environment, 44(1), 34-43. http://dx.doi.org/10.1016/j.buildenv.2008.01.010

You, R., and Zhao, B., 2013, “A Simplified Method for Assessing Particle Deposition Rate in Aircraft Cabins," Atmospheric Environment, 67(2), 80-84.

http://dx.doi.org/10.1016/j.atmosenv.2012.10.046
Yao, R., Chen, Q., 1997, "Prediction of Indoor Climate and Thermal Comfort for Cooling in Ventilated Residence Rooms," HV\&AC, 27 (6): $5-9$.

Yu, Y., and Zhang, G. W., 2008, "Thermal Environment Simulation and Analysis of Radiant Floor Cooling Combining with Displacement Ventilation in the Air Conditioned Room," Refrigeration Air Conditioning \& Electric Power Machinery, 29(119): 11-16.

Yang, P., and Chen, H., 2002, "The Application of PMV-PPD in the Air-conditioning Train," Construction Machinery for Hydraulic Engineering \& Power Station, 23(86): 22-24.

Zhang, T., and Chen, Q., 2007, "Novel Air Distribution Systems for Commercial Aircraft Cabins," Building \& Environment, 42(4), 16751684. http://dx.doi.org/10.1016/j.buildenv.2006.02.014

Zhang, Z., Chen, X., Mazumdar, S., Zhang, T., and Chen, Q., 2009, "Experimental and Numerical Investigation of Airflow and Contaminant Transport in an Airliner Cabin Mockup," Building \& Environment, 44(1), 85-94. http://dx.doi.org/10.1016/j.buildenv.2008.01.012

Zhang H., 2003, "Human Thermal Sensation and Comfort in Transient and Non-uniform Thermal Environments. Berkeley," USA: University of California.

Zhai, J. Z., Zhang, Z., Zhang, W., and Chen, Q., 2007, "Evaluation of Various Turbulence Models in Predicting Airflow and Turbulence in Enclosed Environments by CFD: Part 1-Summary of Prevalent Turbulence Models," HVAC \& R Research, 13(6), 853-870. http://dx.doi.org/10.1080/10789669.2007.10391459

Zhang, Z., Zhang, W., Zhai, J. Z., and Chen, Q., 2007, "Evaluation of Various Turbulence Models in Predicting Airflow and Turbulence in Enclosed Environment by CFD. Part-2: Comparison with Experimental Data from Literature," HVAC\&R Research, 13(6), 871-886. http://dx.doi.org/10.1080/10789669.2007.10391460

Zhang, D., and Ang, H., 2002, "Numerical Simulation of Air Distribution in an Aircraft Cabin," Journal of Nanjing University of Aeronautics \& Astronautics, 34(5), 484-487. 